\title{
Pretreatment Method for Peroxides Decon Water Before GC Analysis of HD, VX, and GD
}

\author{
Mengxue Xu${ }^{1}$, Hongpeng Zhang ${ }^{1}$, Haiyan Zhu ${ }^{1}$, Lianyuan Wang ${ }^{1, a *}$ and Ting Miao ${ }^{1, a *}$ \\ ${ }^{1}$ Institute of Chemical Defence, 102205 Beijing, China
}

\begin{abstract}
Peroxides like sodium percarbonate (SPC) and sodium percarbonate-acetylsalicylic acid (SPCAspirin) can be used to destroy chemical warfare agents (CWAs) such as HD, VX and GD due to the former's oxidation capacity and nucleophilicity. In this paper, experiments were performed to study factors affecting CWAs recovery from peroxides decontaminant water (decon water) and develop the method to recover residual CWAs from peroxides decon water before GC analysis. Results showed that extraction solvent and neutralization were important for high CWA recovery. DCM was more suitable than PE as extractant for most samples except SPC decon water containing HD. Sodium sulfite could well neutralized decontaminant reactivity in decon water. When suitable conditions of simultaneous neutralization and extraction were carried, CWAs recovery from SPC decon water were greater than $90 \%$ at a concentration range of $10 \mathrm{mg}^{1^{-1}}$ to 10000 $\mathrm{mg} \mathrm{l}^{-1}$, the recovery of HD, VX and GD from SPC-Aspirin decon water was more than $90 \%, 80 \%$ and $95 \%$ respectively at a concentration range of $100 \mathrm{mg} \mathrm{l}^{-1}$ to $10000 \mathrm{mg} \mathrm{l}^{-1}$, while CWAs recovery were relatively lower from SPC-Aspirin decon water with CWAs concentration of $10 \mathrm{mg} \mathrm{l}^{-1}$ due to the degradation of CWAs during pretreatment processes.
\end{abstract}

\section{Introduction}

Chemical warfare agents (CWAs), such as HD, VX and GD, have high toxicities [1]. Although most CWAs stocks have been destroyed, they continue to be used in local wars or terrorist attacks.
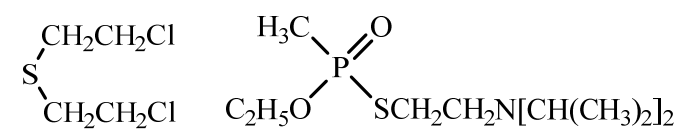

HD<smiles>CC(C)OP(C)(=O)F</smiles>

GD

Decontamination is essential to destroy toxic chemicals on buildings, materials, vehicles, or sensitive equipment, and aqueous solutions of hypochlorite and base are widely used to detoxify CWAs due to their strong oxidation capacity and/or high nucleophilicity [2][3]. However, because of their strong basicity, high oxidability and serious corrosivity, base and hypochlorite were limited in range of application. Peroxide formulas were then developed with high reactivity against CWAs and low corrosivity to metal, plastic, rubber, etc [4-6].

After decontamination, residual CWAs should be evaluated to ensure that surface levels (contact hazard) and desorption concentrations (headspace hazard) have been reduced to acceptable values [4][7]. To obtain accurate results, an efficient method for enriching and separating residual CWAs present at low concentrations in decontamination waste water (decon water) is obviously very important. Organic solvents are often used to extract CWAs from decon water. Dichloromethane (DCM) is the most frequently used extractant in researches [8-11]. Other solvents used to extarct residual agents include n-hexane [12], ethyl acetate [4], methanol [13][14] and petroleum ether (PE) [15] and so on.

However, in addition to CWA residues, excess decontaminants may be present in decon water and it may negatively affect the extraction and subsequent detection of CWAs. Namely, two significant processes occur simultaneously during extraction: enrichment of the CWAs in the solvent based on the partitioning equilibrium constant between the solvent and decon water and continued degradation of the CWAs via reaction with excess decontaminants. The efficiency of extraction depends on which process is dominant. High yields are obtained only when the distribution ratio of CWAs in solvent to decon water is extremely high and the rate of the degradation reaction is relatively low. If the rate of CWA degradation is too high to permit effective extraction, the active ingredient in decon water should be neutralized during pretreatment to avoid excessive losses of CWAs. Examples include the use of sodium thiosulfate as a neutralizer of bleach, DF200 and hypochlorite [15][16]; sodium sulfite to quench the active components of Decon Green and hypochlorite [6][15]. Our previous research proved sodium sulfite was suitable as the neutralizer to obtain high CWAs recovery from hypochlorite decon

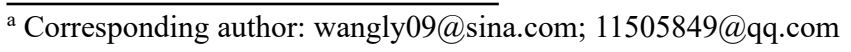


water and it hardly affected extraction of CWAs by PE and DCM [15].

In this work, two decon solutions based on peroxides, namely sodium percarbonate $\left(2 \mathrm{Na}_{2} \mathrm{CO}_{3} \cdot 3 \mathrm{H}_{2} \mathrm{O}_{2}\right.$ or SPC) solution and sodium percarbonate-acetylsalicylic acid solution (SPC-Aspirin solution), were selected as decontaminant which could chemically decompose the aggressive agents through oxidation and hydrolysis. Sodium sulfite worked as neutralizer of decontaminant activity. PE and DCM were for extraction of CWAs. Experiments were carried out to discuss factors affecting the recovery of CWAs and then develop pretreatment methods for SPC and SPC-Aspirin decon water before quantitative determination of residual CWAs with GC.

\section{Experimental}

\subsection{Chemicals}

The toxic agents HD, VX and GD had a purity of $>95 \%$. Because of their high toxicity, they were handled only by well-trained personnel using appropriate safety procedures.

Sodium percarbonate (SPC, A.R.) and acetylsalicylic acid (Aspirin, A.R.) were from Beijing Agents Inc.. SPC solution was prepared through dissolving SPC in water at a ratio of $1: 10$ (wt:vol) to obtain $1 \%$ active oxygen (namely $10000 \mathrm{mg} \mathrm{l}^{-1}$ active oxygen) and $\mathrm{pH} 10.3$. SPCAspirin solution was prepared by adding SPC and Aspirin into distilled water at a ratio of $1: 1: 10$ (wt :wt :V). During the dissolution a reaction occured and peracetic acid $\left(\mathrm{CH}_{3} \mathrm{COOOH}\right.$ or PAA) was produced. The active oxygen of SPC-Aspirin solution was measured to be $1.3 \%$ and the $\mathrm{pH}$ value of SPC-Aspirin solution was measured at 7.3.

Sodium sulfite $\left(\mathrm{Na}_{2} \mathrm{SO}_{3}\right)$ was from Beijing Agents Inc. and $15 \%$ (wt $\%) \mathrm{Na}_{2} \mathrm{SO}_{3}$ was used as neutralizing solutions. PE (boiling range $90 \sim 120^{\circ} \mathrm{C}, \mathrm{AR}$ grade) and $\mathrm{DCM}$ (GC grade) from Bafang Agents Inc. (Beijing, China) were used as extractants. Benzyl sulfide, tributyl phosphate and triethyl phosphate with purity $>98 \%$ were from Alfa Aesar and used as internal standards in GC analysis of HD, VX and GD, respectively.

\subsection{Methods}

\subsubsection{Simulated decon sample}

Simulating decon water with a different CWAs concentration through mixing CWAs and decontaminant is impracticable, because once CWAs encounter decontaminant, they are degraded immediately. Consequently, HD, VX and GD were dissolved in PE or DCM, forming different concentration CWAs solution and presenting residual CWAs concentrations ranging from extremely low to quite high. A simulating decon water with different CWAs residual concentration was prepared in the case of decontaminant solution mixed with CWAs solution [15].

\subsubsection{Decon water pretreatment}

Three groups of experiments (Groups 1 to 3) were performed in 25-ml test tubes as shown in Table 1. First, HD, VX or GD solution was added to the decontaminant or/and neutralization solution and immediately shaken for $20 \mathrm{~s}$. After standing for $10 \mathrm{~min}$, samples of the upper PE phase layer or lower DCM phase layer were removed for residual $\mathrm{HD}, \mathrm{VX}$ or GD determination and recovery calculation [15].

Changes in temperature and $\mathrm{pH}$ value were monitored online by a commercial laboratory $\mathrm{pH} / \mathrm{ORP} /$ temperature meter (HI2221 HANNA). Active oxygen ([O]) in solution could be calculated from equation (1), where $[\mathrm{Cl}]$ was available chlorine in solution quantitatively analyzed by an available chlorine rapid determination instrument $(\mathrm{Q}-$ CL501C).

$$
[O]=\frac{16}{71}[C l]
$$

Table 1. Conditions of the four experiments for decon water pretreatment.

\begin{tabular}{|c|c|c|c|c|}
\hline Group & $\begin{array}{c}\text { (1) } \\
\text { Decon. } \\
\text { sol. }\end{array}$ & $\begin{array}{c}\text { (2) } \\
\text { Neutra. } \\
\text { sol. }\end{array}$ & $\begin{array}{c}\text { (3) } \\
\text { CWA } \\
\text { sol. }\end{array}$ & Procedure \\
\hline 1 & $5 \mathrm{ml}$ & $\begin{array}{c}15 \% \\
\mathrm{Na}_{2} \mathrm{SO}_{3}, \\
5 \mathrm{ml}\end{array}$ & $10 \mathrm{ml}$ & $\begin{array}{c}\text { Mix (1) and } \\
\text { 2, let stand 10 } \\
\text { min, add (3), } \\
\text { shake for 20 s } \\
\text { immediately }\end{array}$ \\
\hline 2 & $5 \mathrm{ml}$ & $\begin{array}{c}\text { None } \\
3\end{array}$ & $10 \mathrm{ml}$ & $\begin{array}{c}\text { Add (3) to (1) } \\
\text { shake for 20 s } \\
\text { immediately }\end{array}$ \\
\hline $5 \mathrm{ml}$ & $\begin{array}{c}15 \% \\
\mathrm{Na}_{2} \mathrm{SO}_{3}, \\
5 \mathrm{ml}\end{array}$ & $10 \mathrm{ml}$ & $\begin{array}{c}\text { Add (2) and } \\
\text { (3) } \\
\text { simultaneously } \\
\text { to (1), shake } \\
\text { for 20 s } \\
\text { immediately }\end{array}$ \\
\hline
\end{tabular}

\section{Results and discussion}

\subsection{Neutralization of peroxides activity}

Before quantitative determination of residual HD, VX and GD by GC-FPD, the CWAs should be extracted with a suitable organic solvent. During this process, active oxygen remaining in the decon water could react with the residual CWAs, resulting in further degradation. Consequently, it is essential to destroy active oxygen before studying the extraction of CWAs in decon water.

$15 \% \mathrm{Na}_{2} \mathrm{SO}_{3}$ was used to neutralize activity of SPC or SPC-Aspirin solution. Changes in active oxygen as well as temperature and $\mathrm{pH}$ during the neutralization process were evaluated to investigate the neutralization conditions. Results showed active oxygen in SPC and SPC-Aspirin solution rapidly reduced to less than $3 \mathrm{mg} \mathrm{l}^{-1}$ within $10 \mathrm{~s}$ when volume ratio of $15 \% \mathrm{Na}_{2} \mathrm{SO}_{3}$ to decon solution is approximately $1: 1$. It meant $\mathrm{Na}_{2} \mathrm{SO}_{3}$ was quite efficient for completely destroying activity of both SPC and SPC- 
Aspirin decon solution. The rate constant of the neutralization reactions $\left(\mathrm{k}_{1, \mathrm{n}}\right)$ reached at least $0.8 \mathrm{~s}^{-1}$, and the half-life period $t_{1 / 2, n}$ were less than 0.9 s. Table 2 showed $\mathrm{k}_{1, \mathrm{n}}$ was more than 3 times higher than the rate constant $\mathrm{k}_{1, \mathrm{~d}}$ of the reaction of SPC or SPC-Aspirin solution with HD, VX or GD in our experiments. It illustrated the strongly competitive capacity of the neutralization solutions.

During neutralization, the temperature of SPC solution and SPC-Aspirin solution rose more than $25^{\circ} \mathrm{C}$ and $20^{\circ} \mathrm{C}$, respectively. It could accelerate self-decomposition of active oxygen in decon solution. In addition, $\mathrm{pH}$ value of SPC solution increased a little and kept at approximately 10.6 when $\mathrm{Na}_{2} \mathrm{SO}_{3}$ solution was used for neutralization. While $\mathrm{pH}$ value of SPC-Aspirin solution dropped slightly from 7.3 to 6.8 . It might negatively affected $\mathrm{VX}$ recovery from decon water because VX could form an ionized product in acid solution and thus prevented its enrichment by extraction with organic solvents.

Table 2. Main neutralization and extraction process parameter.

\begin{tabular}{|c|c|c|c|c|c|c|c|c|}
\hline \multicolumn{4}{|c|}{$\begin{array}{l}\text { Degradation Reaction } \\
\text { (aq.) }\end{array}$} & \multicolumn{2}{|c|}{$\begin{array}{c}\text { Neutralization } \\
\text { Reaction }^{\text {a }} \\
\text { (aq.) }\end{array}$} & \multirow{2}{*}{$\begin{array}{c}\begin{array}{c}\text { Reaction } \\
\text { Competition } \\
(\mathrm{aq} .)\end{array} \\
\mathrm{k}_{1, \mathrm{n}}: \mathrm{k}_{1, \mathrm{~d}}\end{array}$} & \multicolumn{2}{|c|}{ Partitioning Equilibrium } \\
\hline Decon. sol. & CWA & $\begin{array}{l}\mathrm{k}_{1, \mathrm{~d}} \\
\left(\mathrm{~s}^{-1}\right)\end{array}$ & $\begin{array}{c}\mathrm{t}_{1 / 2, \mathrm{~d}} \\
(\mathrm{~s})\end{array}$ & $\begin{array}{l}\mathrm{k}_{1, \mathrm{n}} \\
\left(\mathrm{s}^{-1}\right)\end{array}$ & $\begin{array}{c}\mathrm{t}_{1 / 2, \mathrm{n}} \\
(\mathrm{s})\end{array}$ & & Extractant ${ }^{b}$ & $\begin{array}{l}\text { Distribution Ratio }{ }^{\mathrm{c}} \\
\text { (sol. to aq.) }\end{array}$ \\
\hline \multirow{6}{*}{$\begin{array}{l}\text { SPC, } \\
5 \mathrm{ml}\end{array}$} & \multirow{2}{*}{ HD } & \multirow{2}{*}{0.015} & \multirow{2}{*}{46.2} & \multirow{2}{*}{$>0.9$} & \multirow{2}{*}{$<0.8$} & \multirow{2}{*}{$>50$} & PE & $\geq 19$ \\
\hline & & & & & & & $\mathrm{DCM}$ & $\approx 9$ \\
\hline & \multirow{2}{*}{ VX } & \multirow{2}{*}{$<0.012^{\mathrm{d}}$} & \multirow{2}{*}{$>57.8$} & \multirow{2}{*}{$>0.9$} & \multirow{2}{*}{$<0.8$} & \multirow{2}{*}{$>75$} & $\mathrm{PE}$ & $\geq 19$ \\
\hline & & & & & & & DCM & $>19$ \\
\hline & \multirow{2}{*}{ GD } & \multirow{2}{*}{$<0.25^{\mathrm{d}}$} & \multirow{2}{*}{$>2.8$} & \multirow{2}{*}{$>0.9$} & \multirow{2}{*}{$<0.8$} & \multirow{2}{*}{$>3$} & PE. & $\geq 9$ \\
\hline & & & & & & & $\mathrm{DCM}$ & $>19$ \\
\hline \multirow{6}{*}{$\begin{array}{l}\text { SPC-Aspirin, } \\
\quad 5 \mathrm{ml}\end{array}$} & \multirow{2}{*}{ HD } & \multirow{2}{*}{0.19} & \multirow{2}{*}{3.7} & \multirow{2}{*}{$>0.9$} & \multirow{2}{*}{$<0.8$} & \multirow{2}{*}{$>4$} & PE & $\geq 9$ \\
\hline & & & & & & & DCM & $\approx 19$ \\
\hline & \multirow{2}{*}{ VX } & \multirow{2}{*}{0.012} & \multirow{2}{*}{57.8} & \multirow{2}{*}{$>0.9$} & \multirow{2}{*}{$<0.8$} & \multirow{2}{*}{$>75$} & PE & $<0.1$ \\
\hline & & & & & & & $\mathrm{DCM}$ & $\approx 4$ \\
\hline & \multirow{2}{*}{ GD } & \multirow{2}{*}{0.25} & 2.8 & $>0.9$ & $<0.8$ & & PE & $\approx 2$ \\
\hline & & & 2.0 & -0.9 & -0.0 & $>3$ & $\mathrm{DCM}$ & $>19$ \\
\hline
\end{tabular}

a: neutralization solution was $15 \% \mathrm{Na}_{2} \mathrm{SO}_{3}, 5 \mathrm{ml}$; b: $10 \mathrm{ml}$ of extraction; c: under $50 \mathrm{mg} / \mathrm{l} \mathrm{CWAs}$; d: the speed of VX or GD degradation in SPC solution was slower than that in SPC-Aspirin solution; $20{ }^{\circ} \mathrm{C}$.

\subsection{Extraction of CWAs}

After neutralizing the active oxygen, the effect of two sorts of solvents, PE and DCM, were investigated through comparing the CWA distribution ratio of solvent phase to aqueous decon solution (sol. to aq.) which was calculated based on CWA recoveries. Experiments were carried according to Group 1 conditions in Table 1 and the results were presented in Table 2. Apparently, DCM showed stronger solubility of HD from SPC-Aspirin decon water, $\mathrm{VX}$ and GD from both two peroxides decon water neutralized by $\mathrm{Na}_{2} \mathrm{SO}_{3}$. While for the extraction $\mathrm{HD}$ from SPC decon water, PE was more suitable than DCM. Therefore, in subsequent experiments, DCM was used as extractant to recover VX, GD from SPC decon water and recover CWAs from SPC-Aspirin decon water, PE was used to recover HD from SPC decon water.

\subsection{Pretreatment of HD decon water}

As shown in Table 2, the degradation half-life of HD in SPC solution was $46.2 \mathrm{~s}$ and about 2 times than the $20 \mathrm{~s}$ of shaking in the extraction process, therefore the further degradation of residual HD during extraction was expected to be low. Consequently, high recovery with a good extractant was expected even in the absence of neutralization. However, SPC-Aspirin had very strong reactivity with $H D$ and the $t_{1 / 2, d}$ was $3.7 \mathrm{~s}$. It suggested that the residual HD in SPC-Aspirin decon water was quickly degraded during extraction process and thus a large portion of HD would not be recovered if the activity of SPC-Aspirin decon water was not destroyed in advance. And the results in Table 3 and Table 4 confirmed the deductions above.

Experiments were carried according to Group 2 3 conditions in Table 1 and the results were showed in Table 3 and Table 4. When PE was used to extract HD from SPC decon water directly, HD recovery was greater than $90 \%$ with HD concentrations of $100 \mathrm{mg} \mathrm{l}^{-1}$ to $10000 \mathrm{mg} \mathrm{l}^{-1}$, and it was relatively lower as $84.5 \%$ with HD concentration of $10 \mathrm{mg} \mathrm{l}^{-1}$ (Group 2 in Table 3). When neutralization with $15 \% \mathrm{Na}_{2} \mathrm{SO}_{3}$ and extraction with $\mathrm{PE}$ were carried simultaneously to recover HD from SPC decon water, HD recovery was $94.0 \%$ with HD concentration of $10 \mathrm{mg} \mathrm{l}^{-1}$ and greater than $95 \%$ with HD concentrations of $100 \mathrm{mg} \mathrm{l}^{-1}$ to $10000 \mathrm{mg} \mathrm{l}^{-1}$ (Group3 in Table 3 ). For HD recovery from SPC-Aspirin decon water, extracting by DCM was not suitable and HD recovery was lower than $0.5 \%$ (Group 2 in Table 4). However, HD recovery was greater than $90 \%$ when $15 \% \mathrm{Na}_{2} \mathrm{SO}_{3}$ was used to neutralize activity of decon water and DCM was used to extract HD simultaneously (Group3 in Table 4).

Table 3. HD recovery with (Y)/without(N) neutralization from SPC decon water.

\begin{tabular}{|c|c|c|c|c|}
\hline $\begin{array}{c}\mathrm{C}_{\mathrm{HD}} \\
\left(\mathrm{mg} \mathrm{l}^{-1}\right)\end{array}$ & Group & Neutralization & $\begin{array}{c}\text { HD } \\
\text { Recovery }\end{array}$ & $\begin{array}{c}\text { RSD } \\
(\%)\end{array}$ \\
\hline
\end{tabular}




\begin{tabular}{|c|c|c|c|c|}
\hline & & & $(\%)$ & \\
\hline \multirow{2}{*}{10} & 2 & $\mathrm{~N}$ & 84.5 & 2.0 \\
& 3 & $\mathrm{Y}$ & 94.0 & 5.0 \\
\hline \multirow{2}{*}{100} & 2 & $\mathrm{~N}$ & 94.3 & 0.4 \\
& 3 & $\mathrm{Y}$ & 95.3 & 0.4 \\
\hline \multirow{2}{*}{1000} & 2 & $\mathrm{~N}$ & 97.6 & 1.2 \\
& 3 & $\mathrm{Y}$ & 98.3 & 1.0 \\
\hline \multirow{2}{*}{5000} & 2 & $\mathrm{~N}$ & 97.0 & 1.6 \\
& 3 & $\mathrm{Y}$ & 97.4 & 0.4 \\
\hline \multirow{2}{*}{10000} & 2 & $\mathrm{~N}$ & 96.3 & 0.7 \\
& 3 & $\mathrm{Y}$ & 98.4 & 0.9 \\
\hline
\end{tabular}

SPC decon solution $5 \mathrm{ml} ; 15 \% \mathrm{Na}_{2} \mathrm{SO}_{3} 5 \mathrm{ml}$; extractant PE $10 \mathrm{ml} ; 20{ }^{\circ} \mathrm{C}$.

Table 4. HD recovery with/without neutralization from SPC-Aspirin decon water.

\begin{tabular}{|c|c|c|c|c|}
\hline $\begin{array}{c}\text { CHD } \\
\left(\mathrm{mg} \mathrm{l}^{-1}\right)\end{array}$ & Group & Neutralization & $\begin{array}{c}\text { HD } \\
\text { Recovery } \\
(\%)\end{array}$ & $\begin{array}{c}\text { RSD } \\
(\%)\end{array}$ \\
\hline \multirow{2}{*}{10} & 2 & $\mathrm{~N}$ & $<0.5$ & - \\
& 3 & $\mathrm{Y}$ & 93.2 & 3.8 \\
\hline \multirow{2}{*}{100} & 2 & $\mathrm{~N}$ & $<0.5$ & - \\
& 3 & $\mathrm{Y}$ & 94.9 & 4.4 \\
\hline \multirow{2}{*}{1000} & 2 & $\mathrm{~N}$ & $<0.5$ & - \\
& 3 & $\mathrm{Y}$ & 97.0 & 3.2 \\
\hline \multirow{2}{*}{5000} & 2 & $\mathrm{~N}$ & $<0.5$ & - \\
& 3 & $\mathrm{Y}$ & 99.8 & 2.1 \\
\hline \multirow{2}{*}{10000} & 2 & $\mathrm{~N}$ & $<0.5$ & - \\
& 3 & $\mathrm{Y}$ & 98.9 & 2.8 \\
\hline
\end{tabular}

SPC-Aspirin decon solution $5 \mathrm{ml} ; 15 \% \mathrm{Na}_{2} \mathrm{SO}_{3} 5$ $\mathrm{ml}$; extractant DCM $10 \mathrm{ml} ; 20{ }^{\circ} \mathrm{C}$.

\subsection{Pretreatment of VX decon water}

The reactivity of VX with SPC or SPC-Aspirin was lower than that of HD and the degradation half-life of VX was at least $57.8 \mathrm{~s}$ (Table 2). Therefore, high recovery was excepted with a suitable extractant and without simultaneous neutralization.

The results of experiments showed recoveries of VX with and without neutralization from SPC decon water were close and both greater than $90 \%$ with VX concentrations of $10 \mathrm{mg} \mathrm{l}^{-1}$ to $10000 \mathrm{mg} \mathrm{l}^{-1}$ (Table 5; DCM as extractant).

However, VX recovery was less than $0.5 \%$ when DCM was used to extracted VX directly from SPC-Aspirin decon water (Group 2 in Table 6). It illustrated the degradation of VX during extraction with DCM in SPCAspirin decon water was accelerated, leading to a great loss of VX. While the reason for the acceleration was unclear and further research was needed to study it. When $15 \% \mathrm{Na}_{2} \mathrm{SO}_{3}$ was used to neutralize activity of decon water and DCM was used to extract VX simultaneously from SPC-Aspirin decon water, VX recovery was $74.2 \%$ with VX concentration of $10 \mathrm{mg} \mathrm{l}^{-1}$ and greater than $80 \%$ with VX concentrations of $100 \mathrm{mg} \mathrm{l}^{-1}$ to $10000 \mathrm{mg} \mathrm{l}^{-1}$ (Group 3 in Table 6). VX recoveries were less than $90 \%$, which was probably because the $\mathrm{pH}$ value of SPC-Aspirin decon water neutralized by $\mathrm{Na}_{2} \mathrm{SO}_{3}$ was 6.8 and the acid condition of decon water negatively affected VX recovery.

Table 5. VX recovery with/without neutralization from SPC decon water.

\begin{tabular}{|c|c|c|c|c|}
\hline $\begin{array}{c}\mathrm{C}_{\mathrm{VX}} \\
\left(\mathrm{mg} \mathrm{l}^{-1}\right)\end{array}$ & Group & Neutralization & $\begin{array}{c}\text { VX } \\
\text { Recovery } \\
(\%)\end{array}$ & $\begin{array}{c}\text { RSD } \\
(\%)\end{array}$ \\
\hline \multirow{2}{*}{10} & 2 & $\mathrm{~N}$ & 92.5 & 5.6 \\
& 3 & $\mathrm{Y}$ & 93.1 & 2.2 \\
\hline \multirow{2}{*}{100} & 2 & $\mathrm{~N}$ & 98.4 & 2.7 \\
& 3 & $\mathrm{Y}$ & 98.5 & 0.1 \\
\hline \multirow{2}{*}{1000} & 2 & $\mathrm{~N}$ & 96.1 & 4.5 \\
& 3 & $\mathrm{Y}$ & 99.2 & 2.4 \\
\hline \multirow{2}{*}{5000} & 2 & $\mathrm{~N}$ & 95.3 & 0.7 \\
& 3 & $\mathrm{Y}$ & 99.5 & 0.4 \\
\hline \multirow{2}{*}{10000} & 2 & $\mathrm{~N}$ & 97.1 & 1.8 \\
& 3 & $\mathrm{Y}$ & 95.5 & 1.0 \\
\hline
\end{tabular}

SPC decon solution $5 \mathrm{ml} ; 15 \% \mathrm{Na}_{2} \mathrm{SO}_{3} 5 \mathrm{ml}$; extractant DCM $10 \mathrm{ml} ; 20{ }^{\circ} \mathrm{C}$.

Table 6. VX recovery with/without neutralization from SPC-Aspirin decon water.

\begin{tabular}{|c|c|c|c|c|}
\hline $\begin{array}{c}\mathrm{CVx}_{\mathrm{V}} \\
\left(\mathrm{mg} \mathrm{l}^{-1}\right)\end{array}$ & Group & Neutralization & $\begin{array}{c}\text { VX } \\
\text { Recovery } \\
(\%)\end{array}$ & $\begin{array}{c}\text { RSD } \\
(\%)\end{array}$ \\
\hline \multirow{2}{*}{10} & 2 & $\mathrm{~N}$ & $<0.5$ & - \\
& 3 & $\mathrm{Y}$ & 74.2 & 5.1 \\
\hline \multirow{2}{*}{100} & 2 & $\mathrm{~N}$ & $<0.5$ & - \\
& 3 & $\mathrm{Y}$ & 80.9 & 4.6 \\
\hline \multirow{2}{*}{1000} & 2 & $\mathrm{~N}$ & $<0.5$ & - \\
& 3 & $\mathrm{Y}$ & 83.4 & 3.7 \\
\hline \multirow{2}{*}{5000} & 2 & $\mathrm{~N}$ & $<0.5$ & - \\
& 3 & $\mathrm{Y}$ & 85.2 & 3.8 \\
\hline \multirow{2}{*}{10000} & 2 & $\mathrm{~N}$ & $<0.5$ & - \\
& 3 & $\mathrm{Y}$ & 87.4 & 2.8 \\
\hline
\end{tabular}

SPC-Aspirin decon solution $5 \mathrm{ml} ; 15 \% \mathrm{Na}_{2} \mathrm{SO}_{3} 5 \mathrm{ml}$; extractant DCM $10 \mathrm{ml} ; 20{ }^{\circ} \mathrm{C}$.

\subsection{Pretreatment of GD decon water}

The main active ingredient in SPC and SPC-Aspirin solution was $\mathrm{HOO}^{-}$and $\mathrm{CH}_{3} \mathrm{COOO}^{-}$, respectively. And they could react with GD due to their nucleophilicity. The reaction of GD with SPC-Aspirin occurs rapidly and the half-life was about $2.8 \mathrm{~s}$ (Table 2). Since the nucleophilicity of $\mathrm{HOO}^{-}$was weaker than $\mathrm{CH}_{3} \mathrm{COOO}^{-}$, thus the half-life of GD degradation in SPC solution would be longer than $2.8 \mathrm{~s}$. However, extraction with DCM led to a decrease in solvent polarity and formation of a heterogeneous solution, greatly weakening the nucleophilicity of $\mathrm{CH}_{3} \mathrm{COOO}^{-}$and $\mathrm{HOO}^{-}$. As a result, less residual GD was degraded during extraction.

The recovery of GD reached greater than $90 \%$ for SPC samples with residual GD above $100 \mathrm{mg} \mathrm{l}^{-1}$, and there was no significant difference between the two pretreatment approaches, i.e., with or without neutralization (Table 7). While GD recovery with neutralization was apparently higher when GD concentration was $10 \mathrm{mg} \mathrm{l}^{-1}$.

GD recovery without neutralization from SPC-Aspirin 
decon water was relatively lower than that from SPC solution due to the former's stronger neucleophilicity, and it was as low as $68.3 \%$ with GD concentration of 10 mg $1^{-1}$ (Group 2 in Table 8). Therefore, neutralizing activity of decon water and extracting GD at the same time was a more suitable method for the pretreatment of SPCAspirin decon water. And it could obtain GD recovery of more than $95 \%$ with GD concentration of $100 \mathrm{mg} \mathrm{l}^{-1}$ to $10000 \mathrm{mg}^{-1}$ (Group 3 in Table 8). When the concentration of GD was $10 \mathrm{mg} \mathrm{l}^{-1}$, GD recovery was relatively lower as $83.0 \%$ because GD might degrade continuously to some extent during the pretreatment.

Table 7. GD recovery with/without neutralization from SPC decon water.

\begin{tabular}{|c|c|c|c|c|}
\hline $\begin{array}{c}\mathrm{C}_{\mathrm{GD}} \\
\left(\mathrm{mg} \mathrm{l}^{-1}\right)\end{array}$ & Group & Neutralization & $\begin{array}{c}\text { GD } \\
\text { Recovery } \\
(\%)\end{array}$ & $\begin{array}{c}\text { RSD } \\
(\%)\end{array}$ \\
\hline \multirow{2}{*}{10} & 2 & $\mathrm{~N}$ & 87.6 & 0.9 \\
& 3 & $\mathrm{Y}$ & 99.8 & 4.5 \\
\hline \multirow{2}{*}{100} & 2 & $\mathrm{~N}$ & 95.8 & 1.7 \\
& 3 & $\mathrm{Y}$ & 98.1 & 4.5 \\
\hline \multirow{2}{*}{1000} & 2 & $\mathrm{~N}$ & 98.2 & 1.1 \\
& 3 & $\mathrm{Y}$ & 99.3 & 1.7 \\
\hline \multirow{2}{*}{5000} & 2 & $\mathrm{~N}$ & 93.2 & 2.1 \\
& 3 & $\mathrm{Y}$ & 97.9 & 0.7 \\
\hline \multirow{2}{*}{10000} & 2 & $\mathrm{~N}$ & 95.6 & 5.3 \\
& 3 & $\mathrm{Y}$ & 97.9 & 4.9 \\
\hline
\end{tabular}

SPC decon solution $5 \mathrm{ml} ; 15 \% \quad \mathrm{Na}_{2} \mathrm{SO}_{3} 5 \mathrm{ml}$; extractant DCM $10 \mathrm{ml} ; 20{ }^{\circ} \mathrm{C}$.

Table 8. GD recovery with/without neutralization from SPC-Aspirin decon water.

\begin{tabular}{|c|c|c|c|c|}
\hline $\begin{array}{c}\mathrm{C}_{\mathrm{GD}} \\
\left(\mathrm{mg} \mathrm{l}^{-1}\right)\end{array}$ & Group & Neutralization & $\begin{array}{c}\text { GD } \\
\text { Recovery } \\
(\%)\end{array}$ & $\begin{array}{c}\mathrm{RSD} \\
(\%)\end{array}$ \\
\hline \multirow{2}{*}{10} & 2 & $\mathrm{~N}$ & 68.3 & 2.0 \\
& 3 & $\mathrm{Y}$ & 83.0 & 6.3 \\
\hline \multirow{2}{*}{100} & 2 & $\mathrm{~N}$ & 91.3 & 5.6 \\
& 3 & $\mathrm{Y}$ & 99.3 & 3.7 \\
\hline \multirow{2}{*}{1000} & 2 & $\mathrm{~N}$ & 90.6 & 6.4 \\
& 3 & $\mathrm{Y}$ & 99.0 & 4.5 \\
\hline \multirow{2}{*}{5000} & 2 & $\mathrm{~N}$ & 92.3 & 2.4 \\
& 3 & $\mathrm{Y}$ & 99.2 & 0.8 \\
\hline \multirow{2}{*}{10000} & 2 & $\mathrm{~N}$ & 93.4 & 1.2 \\
& 3 & $\mathrm{Y}$ & 99.9 & 2.6 \\
\hline
\end{tabular}

SPC-Aspirin decon solution $5 \mathrm{ml} ; 15 \% \mathrm{Na}_{2} \mathrm{SO}_{3} 5$ $\mathrm{ml}$; extractant DCM $10 \mathrm{ml} ; 20{ }^{\circ} \mathrm{C}$.

\section{Conclusions}

Among the factors affecting CWAs recovery from decon water, the choice of solvent was important and it laid the foundation for high CWAs recovery. The present study revealed that DCM was more suitable than $\mathrm{PE}$ as solvent for extraction of CWAs from SPC and SPC-Aspirin decon water, excepting for SPC decon water containing HD. In addition, neutralization was required for high recovery, particularly for samples with low CWA concentrations and/or stronger decontaminant reactivity. And 15\% $\mathrm{Na}_{2} \mathrm{SO}_{3}$ was demonstrated to be a suitable neutralization solution for high CWA recovery.

When the optimized conditions of simultaneous neutralization with $\mathrm{Na}_{2} \mathrm{SO}_{3}$ and extraction with DCM for $\mathrm{VX}, \mathrm{GD}$ or PE for HD were used, CWA recoveries of greater than $90 \%$ could be obtained from SPC decon water with CWA concentrations of $10 \mathrm{mg} \mathrm{l}^{-1}$ to $\quad 10000$ mg ${ }^{-1}$. When simultaneous neutralization with $\mathrm{Na}_{2} \mathrm{SO}_{3}$ and extraction with DCM were carried for the pretreatment of SPC-Aspirin decon water, the recovery of HD, VX and GD was greater than $90 \%, 80 \%$ and $95 \%$ respectively, with CWA concentrations of $100 \mathrm{mg} \mathrm{l}^{-1}$ to $10000 \mathrm{mg} \mathrm{l}^{-1}$. When CWAs concentration were $10 \mathrm{mg} \mathrm{l}^{-1}$, CWAs recovery were relatively lower because CWAs could degrade continuously during pretreatment processes.

\section{References}

1. H. John, B. Frank, S. Dirk, K. Kai, W. Franz, T. Horst, R. C. Gupta, Academic Press, New York. pp. 817-874 (2015)

2. S. S. Talmage, A. P. Watson, V. Hauschild, N. B. Munro, J. King, Curr. Org. Chem. 11, 285-298 (2007)

3. Y. C. Yang, J. A. Baker, J. R. Ward, Chem. Rev. 92, 1729-1743 (1992)

4. G.W. Wagner, L. Procell, D. Sorrick, B. MacIver, A. Turetsky, J. Pfarr, D. Dutt, M. Brickhous, U.S. Scientific Conference on Chemical and Biological Defense Research. Hunt Valley, Maryland on 15-17 November 2004, ADM 001849 (2004)

5. G. W. Wagner, L. R. Procell, J. B. Kiple, M. J. S. Taylor, Y. C. Yang, U.S. Army Research, Development and Engineering Command (2005)

6. G. W. Wagner, L. R. Procell, D. C. Sorrick, G. E. Lawson, C. M. Wells, C. M. Reynolds, D. B. Ringelberg, K. L. Foley, G. J. Lumetta, D. L Blanchard, Jr., Ind. Eng. Chem. Res. 49, 3099-3105 (2010)

7. N. B. Munro, S. S. Talmage, G. D. Griffin, L. C. Waters, A. P. Watson, J. F. King, V. Hauschild, Environ. Health Perspect. 107, 933-974 (1999)

8. P. Nicoleta, P. Razvan, P. Andrada, T. Constantin, S.Vasile, N. Florentina, F. Mihaela, N. Stefan, C. R. Chimie. 21, 339-345 (2018)

9. S. Popiel, Z. Witkiewicz, A. Szewczuk, J. Hazard. Mater. B. 123, 94-111 (2005)

10. L. H. Qi, G. M. Zuo, Z. X. Cheng, H. Y. Zhu, S. M. Li,Water Sci. \& Tech. 66 (7), 1377-1383 (2012)

11. F. B. Hopkins, M. R. Gravett, A. J. Self, M. Wang, C Hoe-Chee, N. Lee Hoi Sim, J. T. A. Jones, C. M. Timperley, J. R. Riches, Anal. Bioanal Chem. 406, 5111-5119 (2014)

12. H. Stone, D. See, A. Smiley, A. Ellingson, J. Schimmoeller, L. Oudejans, J. Hazard. Mater. 314, 59-66 (2016)

13. S. S. Aleksenko, J. Anal. Chem. 67 (2), 82-97 (2012) 
Liquid chromatography with mass-spectrometric detection for the determination of chemical warfare agents and their degradation products..

14. J. Choi, D. S. Moon, S. G. Ryn, B. Lee, W. B. Ying, K. J. Lee, Polymer. 138, 146-155 (2018)

15. M. X. Xu, L. Y. Wang, H. Y. Zhu, H. P. Zhang, J. Liang, X. G. Wang, Z. X. Cheng, Y. F. Zhu, Water Sci. \& Tech. 83 (5), 985-992 (2021)

16. L. Oudejans, J. O'Kelly, A. S. Evans, B. W. Ceradini, A. Touati, D. Tabor, E. G. Snyder, J. Environ. Chem. Eng. 4, 2745-2753 (2016) 